\section{Organización Pública del Turismo en Venezuela - Proceso de Descentralización Administrativa}

\section{Rafael Rodríguez Acevedo}

RESUMEN: Trabajo de investigación, cuyo objetivo se fundamenta en el diagnóstico y evaluación de la estructura y funcionalidad de la Organización Pública del Turismo en Venezuela, a la luz del proceso de descentralización administrativa acometida por el Estado durante el primer quinquenio de los años noventa, en relación con el análisis de las bases jurídico-administrativas afines a las competencias turísticas.

PALABRAS CLAVES: Turismo y estado; organización pública; descentralización administrativa; competencias turísticas.

ABSTRACT: Research paper, whose objetive is founded in a methodological diagnosis and evaluation of the structures and funtionality of tourism public organizations in Venezuela, in the light of the administrative decentralization process, attended by the state during the first five years of 90 s related to the analysis of juridical-administrative bases and touristic competences.

KEY WORDS: Tourism and state; public organization; administrative decentralization, touristic competences.

\section{Introducción}

La influencia económica derivada de la sumatoria de gestiones individuales atrae desde principios de siglo la acogida favorable del Estado, institución de la sociedad que le otorga al Turismo un rol preponderante como consecuencia de la

1. Licenciado em Administração de Empresas pela U. N. E. "Simón Rodriguez". Mestre em Planejamento Turistico pela U.N.E. "Francisco Miranda". Pesquisador na Universidade Simón Bolivar (10 anos). Consultor de empresas privadas

End. para corresp.:Apartado Postal,n 314-La Guaira-D.F. Venezuela. Fax:5831-722313/722315.E-mail:rodrig@usb.ve. capacidad real y potencial que presenta, al impulsar y multiplicar un amplia gama de beneficios colectivos; comenzando por ende, a partir de la segunda mitad del siglo XX un vínculo complementario entre un sector privado que activa a las fuerzas dela ofertay la demanda, y un sector político que se encarga de establecery fomentar las bases legales, organizacionales y programáticas sobre las que se armonizarán y desarrollarán las acciones empresariales con las gubernamentales.

Por consiguiente, para cumplir con los roles que se subroga para sí, o que le son impuestos, el Estado posee un conjunto de instituciones armónicas y consonantes bajo la forma de administración pública, a la cual corresponde la ejecución de los fines esperados por el espectro social, contando para ello con una estructura orgánica y funcional, que de hecho es mas o menos compleja en una relación proporcional a la jerarquía que el país le otorga.

Comoresultado, el enlaceentre administración pública y actividadturistica aunque cronológicamente tardía, no fué condición limitante que le restó oportunidad a laparticipación oficial. Sin embargo, al hacer abstracción, la historia contemporánea del turismo venezolano ha estado también ligada a la concepción organizativa que ha hecho de ella un aparato burocrático central que apenas se está incorporando a la descentralización administrativa y a la transferencia de competencias respectivamente.

Sustentado en dicho planteamiento, ésta investigación tiene por objeto diagnósticar y evaluar a la organización estructural y funcional que vincula a Estado, a la administración pública y al desarrollo de la actividad turística en Venezuela, utilizando en primera instancia la aplicación de un modelo teórico para el diagnóstico evaluativo de las funciones administrativas relacionadas con las organizaciones públicasque le han sido delegadas las competencias turísticas; y en segundo lugar el estudio de los dos instrumentos jurídico-administrativos relacionados con la materia de la descentralización del turismo: La Ley de Turismo ( $3^{\mathrm{a}}$ versión promulgada el 18 de Diciembre de 1992) y la Ley Orgánica de Régimen Municipal (reglamento parcial n. 1 promulgado el 5 de Diciembre de 1990).

\section{Consideraciones Teóricas Aplicada a la Administración Pública}

\section{Política y Planificación Macrosectorial}

\section{De la Teoría a los Fines Económicos y Sociales}

Toda política que expresa una estrategia de crecimiento y desarrollo se evidencia por medio de grados y etapas de acción del Estado, que van desde el intervencionismo, pasando por el dirigismo, hasta otras modalidades.

Teóricamente la planificación en el estricto sentido constituye una intervención deliberada, que se fundamenta en el conocimiento racional del proceso socioeconómico y de sus leyes (Comisión..., 1985). 
Es una actividad compleja y continua, con diferentes funciones, tareas y etapas que se desarrollan en el tiempo. Es un conjunto de actos que configuran un proceso singular dentro de otro proceso más general, el de las decisiones del poder político. La actividad planificadora del Estado, su formulación y ejecución suponen y exigen una decisión política permanente.

Habría que analizar hasta que punto, fruto de la interpretación y aplicación que de éste instrumento de desarrollo se ha tenido, el Estado Venezolano durante varios decenios justificó el número, ámbito y envergadura de sus intervenciones, y el grado de inherencia, regulación, promoción y participación directa en formas, sectores y actividades que a nombre del interés público se asumían como responsabilidad del Estado, y por consiguiente conocer el porqué a pesar de los intentos de planificación económica hasta ahora realizados y de la apertura hacia una fórmula o concepción neo-liberal, se ha mantenido una configuración y dinámica de la economía y de la sociedad donde se entronizan los mismos esquemas de generación, distribución y uso de la riqueza y el poder.

\section{De la Planificación Económica a la Planificación Administrativa}

Después de haberse explicado que la planificación es, junto con otros instrumentos, elemento indispensable para acelerar el cambio de los niveles económicos y sociales hacia otros estados de bienestar, porque este cambio debe ser consciente, coherente y equilibrado. Resulta imperativo despejar los aspectos concernientes a la planificación administrativa.

La administración pública es parte de la estructura social que se requiere modificar, buscando el mejoramiento del proceso de desarrollo; ya que está de más expresar, que es uno de los elementos que sirven para impulsar o detener el cumplimiento de los objetivos de la planificación en el momento de operativizarlos.

Así, que para acelerar este cambio social, se requiere de aplicar a la administración pública los mismos principios teóricos conceptuales de la planificación que se emplean en otras áreas, conduciendo por extensión al uso de la denominada planificación administrativa. Jacome (1975:64) la define como:

(...) el proceso permanente por medio del cual se establecen objetivos administrativos a alcanzarse en un período determinado por medio de políticas, planes y el empleo eficiente de los recursos administrativos existentes, para conseguir la optimización de los niveles administrativos.

De dicho concepto, se deduce que al considerar las posibilidades de uso, se procura la máxima eficiencia en el empleo de los recursos administrativos en todas las fases de la planificación económica con el fin de acelerar el desarrollo, aumentando el rendimiento de los mismos para conseguir el correspondiente aumento de bienes y servicios. Es bajo ésta filosofía como la planificación administrativa adquiere una nueva razón de ser y su utilidad es claramente comprendida.

Además de tener bien definido su significado y alcance, es importante conocer el procedimiento de diseño, diagnóstico y evaluación de la Administración Pública en Venezuela.

\section{Metodología para la Investigación y Análisis de la Administración Pública}

La planificación administrativa debe ajustarse a un procedimiento de acción racional, comenzando por la investigación y análisis de la administración pública, de modo de poder saber cómo está constituida y cuales son sus problemas, procurando alcanzar la cuantificación de éstos y su clasificación en un orden de importancia.

Continúa pues, con la fijación de objetivos generales y las líneas de política donde se relacionan los diferentes sectores, se hace el balance de los recursos a emplear, se identifican las prioridades de acción y se escoge la estrategia a largo plazo que será usada para llegar a los objetivos propuestos.

Luego pasa a el análisis y programación sectorial del aparato administrativo, comenzandopor los sectores prioritarios dentro de la acción de desarrollo nacional Cada uno de los sectores programados como un todo homogéneo y coherente no son cuerpos aislados de acción unilateral, tienen una serie de interrelaciones; existen áreas en las cuales no se puede trazar una línea divisoria ampliamente visible entre ellos. Estas interrelaciones también deben ser conocidas, analizadas y tomadas en cuenta en la programación administrativa sectorial.

Después de tener dilucidado el escenario administrativo en forma global y sectorial se iniciala ejecuciónpor medio de proyectosbien elaborados y correctamente aplicados en cada uno de los sectores. Para estos efectos no existe una frontera de culminación ideal, todo lo contrario, se mantendrá un análisis continuo de la situación, así como de control y ajuste de lo programado de tal modo que en el corto, mediano y largo plazo se lleguen a los objetivos fijados, cuya suma no es otra que la modernización de la administración pública.

\section{La Reforma Administrativa}

Al observarse la evolución de la Administración Pública Venezolana, se puede apreciar que se ha realizado una gran cantidad de modificaciones en la distribución de autoridad y responsabilidad entre los entes participantes del poder central y la frecuente creación, modificación y eliminación de organismos y funciones gubernamentales.

Estos cambios no han obedecido evidentemente a un plan coherente de ampliación y reorganización, sino que más bien han correspondido a crecimiento 
por agregación; por otro lado, se ha dado el caso persistente en el cual la reforma administrativa se acarició como el único objetivo de aumentar la eficacia de la acción gubernamental y la superación de obstáculos a problemas más o menos identificables. En estos casos las implicaciones de estos cambios en el desarrollo nacional fueron tomadas en cuenta solo indirectamente y la acción reformista no tuvo relación alguna con la programación socioeconómica

La experiencia en materia de reforma se ha venido traduciendo en acciones aisladas destinadas a modificar segmentos del aparato Estatal con el fin de resolver losproblemas de escasos recursosfinancieros para atender las necesidadesinminentes del grueso poblacional visto como una decisión política y no como el proceso de transición de un Estado tradicional a uno nuevo, dinámico y flexible donde queden implicados al mismo tiempo un cambio de actitudes, usos y costumbres reformistas que se encuentran profundamente arraigados en algunos sectores de la sociedad venezolana.

La adopción de la planificación administrativa y dentro de ella la reforma administrativa es un paso significativo, porque se puede obtener de su ejecución la optimización en el uso de los recursos con el fin de aumentar el ritmo de desarrollo y producir cambios de un nivel socioeconómico a otro superior. Sin embargo, no se podía esperar que fuera fácil la introducción de la disciplina, racionalidad y eficiencia en un ambiente gubernamental viciado y deficiente.

La oposición y resistencia a la planificación y a la verdadera reforma ha provenido de los grupos tradicionales de poder político y financiero incrustados en el interior de los gobiernos de turno.

Por lo tanto, el Estado contrariamente a que propicia posiciones reformistas simplificación del aparato burocrático, transferencia de competencias); por citar dos casos, continúa atado a una indefinición estructural y funcional que arrastra a todos los participantes de la sociedad y a los sectores económicos.

\section{Intervencionismo del Estado en la Actividad Turística}

\section{Origen de la Actuación}

De la revisión histórica del turismo tanto en el ámbito internacional como nacional se ha obtenido como consecuencia que son muy pocas las acciones reflexivas desde la posición del Estado que realmente pueden ser identificadas hasta la Revolución Industrial, en uno u otro caso estuvo más cercano a los indicadores que respondían a las conquistas del tiempo libre y a la libertad de movimientos.

En el transcurso que el fenómeno turístico se fue posesionando tanto de los viajeros como de los ofertantes de servicios, se activaron en ese espacio geoeconómico la circulación de los individuos, de las cosas materiales y del dinero.

\section{Desarrollo}

No había el Estado percibido en toda su magnitud la influencia envolvente y entusiasta del Turismo, sino a partir en que comienzan a percibirse los efectos económicos inducidos por el trabajo y las ideas de los empresarios de finales del siglo XIX. De alli hacia adelante se da inicio a todo un proceso de incorporación, crecimiento y madurez del Turismo.

Pero, para que ello se facilitara era necesario la concurrencia de los fines supremos que persiguen las grandes actividades del Estado Moderno con los órganos que la constituyen, distinguiéndose por supuesto las funciones legislativas, ejecutivas y judiciales. Estas funciones se reagrupan en los órganos agregados a los Estados, siendo a estos efectos por la vía del gobierno y específicamente por medio de la Administración Pública el ente responsable de la ejecución práctica de los fines ansiados por el gran conglomerado social.

Asi pues, el Turismo tardó siglos en merecer una ubicación en la estructura organizativa del Estado y por consecuencia de la Administración Pública, más éste hecho no le impidió al intervencionismo oficial enlazarse a un conjunto de cuatro grandes períodos que según el profesor Krapf (1963), en concordancia a las acciones cumplidas las identificó y distribuyópor periódos, los cuales son enumerados en el Cuadro 1.

\section{CUADRO 1 - PERIODOS DISTRIBUIDOS POR ACCIONES} ORGANIZACIONALES OFICIALES O PRIVADOS NIVEL INTERNACIONAL

\begin{tabular}{|c|c|c|c|}
\hline Periodo & Ubicación & Denominación & Acciones \\
\hline $1 \%$ & Finales del siglo XIX & Interayuda Profesional & $\begin{array}{l}\text { Aparecen organizaciones } \\
\text { privadas }\end{array}$ \\
\hline 2 क & antes I Guerra Mundial & Propaganda & $\begin{array}{l}\text { Conciencia económica } \\
\text { del valor del Turismo }\end{array}$ \\
\hline $3 \approx$ & Crisis años 30 & Proteccionismo & $\begin{array}{l}\text { Crean organizaciones } \\
\text { gubernamentales }\end{array}$ \\
\hline $4^{\circ}$ & después II Guerra Mundial & Adaptación & $\begin{array}{l}\text { Análisis y acercamiento } \\
\text { a las tendencias } \\
\text { modernas dejando } \\
\text { entrever un periodo } \\
\text { adicional }\end{array}$ \\
\hline 5。 & Mediados años 60 & Planificación & Racionalización \\
\hline
\end{tabular}




\section{Introducción al Estudio de las Competencias Turísticas}

\section{Definición}

Cuando el turismo se desarrolla en una amplia zona que abarca una extensión geográfica-administrativa que se despliega más allá del Municipio, la región o el país, se hace imprescindible un espíritu de coexistencia que permita acometer todas aquellas cuestiones que le atañen. Es imprescindible darse cuenta que el turista o la empresa llegan a una zona en la que no se percibe la diferenciación jurisdiccional del organismo responsable de la actividad.

De allí, que es un compromiso del Estado definir la separación de las competencias por grado, territorio o materia.

Al considerar una acepción estrictamente jurídica, se le podrá conceptualizar como la aptitud de los órganos del Estado. Facultad expresada en una norma jurídica preexistente. Complejo defunciones atribuidas a un órgano administrativo, o como la medida de la potestad atribuida a cada órgano (Alessi, 1990: 102).

\section{Fundamentos Jurídicos-Administrativos}

La constitución y la leyes sientan las bases jurídicas de las competencias que corresponden a los niveles territoriales del Estado siendo: la Nación, los Estados o Entidades Federales y los Municipios.

- Nacional o República

La Carta Magna expresa que "La República de Venezuela es un Estado Federal en los términos consagrados por ésta constitución" (art 2do ). Por lo tanto, se determina inequívocamente a las competenciaspertenecientes al Poder Nacional, así comolas directrices del ámbito de la Administración Municipal, consecuentemente precisa que "Es de la competencia de cada Estado: Todo lo que no corresponda, de conformidad con ésta constitución, a la competencia nacional o municipal" (art 17 ord. $7 \mathrm{mo}$ )

- Estados y/o Entidades Federales

El artículo $17^{\circ}$ le atribuye un conjunto de materias y el $18^{\circ}$ expresa sobre las prohibiciones respectivamente. Las competencias que le faculta la constitución a los Estados son básicamente de tipo administrativo y material pudiéndose citar:

i) organización de sus poderes públicos.

ii) organización de sus municipios.

iii) administración de sus bienes y la inversión del situado constitucional y demás ingresos que le corresponden.

iv) uso del crédito público.

\section{- Municipal}

La constitución en el artículo $30^{\circ}$ declara:

Es de competencia municipal el gobierno y la administración de los intereses peculiares de la Entidad, en particular cuanto tenga relación con sus bienes e ingresos y con las materias propias de la vida local, tales como urbanismo, abastos, circulación, cultura, salubridad, asistencia social, institutos populares de crédito, turismo y politica municipal. La ley podrá atribuir a los municipios competencia exclusiva en determinadas materias, así como imponerles un minimo obligatorio de servicios.

Acto seguido, la Ley Orgánica de Régimen Municipal precisa:

i) En el artículo $36^{\circ}$ expresa

Los municipios, para la gestión de sus intereses y el ámbito de sus competencias, podrá promover toda clase de actividades y prestar cuanto servicios públicos contribuyan a satisfacer las necesidades $y$ aspiraciones de la comunidad.

ii) El artículo $37^{\circ}$ refiere:

El municipio cooperará en una serie de materias atribuidas al poder nacional particularmente en el área de salubridad pública, de los servicios sociales, en la organización de la producción, asi como en la construcción de caminos y vias rurales.

iii) El artículo $38^{\circ}$ regula los servicios mínimos que deben de garantizar los municipios a los vecinos en proporción al número de habitantes.

iv) Para finalizar el artículo 39 define las competencias de los Distritos Metropolitanos.

\section{Atribuciones Funcionales}

El Estado utiliza las más amplias potestades para cumplir con los objetivos que se reserva por vocación y propiedad; de allí que, instala toda una estructura admirustrativa encargada de orientar, promover, incentivar y regular los procesos socioeconómicos.

Hallándose las actividad turística debidamente argumentada y vistas sus implicaciones, define el campo de actuación funcional del Ente responsable de la ejecución de las políticas. 
Desde la perspectiva de las facultades que le son atribuidas según la Ley, los estatutos y los lineamientos programáticos, en los términos indicativos, se pueden enumerar el siguiente gripo de funciones:

a) captación y consolidación de mercados

i) investigación y estudios (segmentos, perfiles)

ii) fijación de cuotas de mercado (en plazos)

iii) información (oficina exterior, aeropuertos, puertos)

iv) promoción (publicidad, RRPP)

v) organización de eventos (nacionales, internacionales);

b) fomento y desarrollo de la planta turística

i) promoción de inversiones

ii) reducción impositiva - incentivos fiscales

iii) otorgamiento de concesiones

iv) prestar asistencia técnica

v) evaluación de proyectos

vi) organización y/o asistencia a bolsas de turismo;

c) ordenación

i) del espacio turístico

- formulación de planes rectores

- determinación de interés turístico

- elaboración del inventario del patrimonio turístico

- fijación de standares y capacidades de planificación del espacio físico

ii) de la planta turística

- fijación de requisitos administrativos y técnicos

- autorización de funcionamiento

- clasificación y categorización de servicios

- control, inspección y fiscalización de servicios

d) coordinación interregional y municipal

i) fomentar la participación regional

ii) prestar asistencia técnica

iii) delegación de competencias;

e) formación de recursos humanos
i) detección de necesidades de capacitación y adiestramiento
ii) elaboración de diagnósticos

iii) coparticipación en la definición de políticas específicas;

f) entre otras funciones.

\section{Problemática Derivada}

La promulgación de la Ley Orgânica de Descentralización, Delimitación y Transferencia de Competencias del Poder Público en si misma, trae como consecuencia la resolución de un asunto que tradicionalmente se encontraba "enquistado" en la estructura organizativay mental delEstado y de los funcionarios gubernamentales; si bien parte de la necesidad de actualización de la materia del derecho administrativo, queda por solventar los procedimientos mediante los cuales se operacionalicen las funciones transferidas desde el Poder Nacional hasta los Estados y Municipios.

\section{La Descentralización de los Poderes y el Turismo}

Los estamentos provincialesy municipales, presentan desniveles y carencias organizacionales, técnicas y de control para acometer la Descentralización. Al citar una publicación de la Comisión para la Reforma del Estado (Comisión..., 1989: 25) donde se asevera:

La trayectoria histórica institucional de las gobemaciones y municipios dentro de un complejo sistema de intereses local-nacional, ha determinado que estas organizaciones se hallan visto reducidas progresivamente, a actuar comogestores de recursos menores de los órganos nacionales con un rol politico-policial de escasa autonomia. EL juicio generalizado de lapoblación es que las gobemaciones y municipios son deficientes y que lejos de atender los planteamientos formulados por la comunidad han distraido los recursos en actividades de poca significación y que se corresponden más con los intereses partidistas.

Por consiguiente, subyace el mensaje, que de no asumirse la reforma administrativa en forma planificada, y de no practicarse asi, pudiera revertir los fines de la política descentralizadora, por lo que es imprescindible precisar: donde y como regular y dinamizar las competencias transferidas.

En relación al turismo, el proceso descentralizador se encuentra aún en la fase de sustentación, tanto en su parte jurídica como en la organizativa propiamente dicha.

\section{- Parte jurídica}

De inicio, es preciso acotar, que la actividad turística se encuentra juridicamente adscrita a las competencias municipales, quedando definida en forma positiva en el título III de la Ley Orgánica de Régimen Municipal, en el articulo $36^{\circ}$, presenta una conjunción de numerales explícitos e intervinieres que en su forma más extensa coliden con el espiritu del turismo (Congreso..., 1989): 
i) numerales explícitos:

El numeral $11^{\circ}$, lo destaca terminantemente (Congreso..., 1989);

Organizar y promover las feriasy festividades populares asi como estimular las actividades dirigidas al desarrollo del turismo local.

ii) numerales intervinientes:

De un total de 17 numerales que estipulan a las competencias, 14 de ellos se ajustan relativamente a 10 campos aplicados del Turismo, según consta en la relación de intervenciones que a título indicativo se mencionan en el Cuadro 2 (Congreso..., 1989).

\section{CUADRO 2 - RELACIÓN DE NUMERALES CON APLICACIÓN AL TURISMO}

\begin{tabular}{lll}
\hline Numeral & $\begin{array}{l}\text { Campos Aplicados a Escala } \\
\text { Regional y/o local }\end{array}$ \\
\hline Nenominación \\
\hline lero, 2do, 4to y 12do & 1 & Infraestructura Turistica \\
3ero & 2 & Planificaclón Turística Regional \\
5to & 3 & Equipamiento Turistico \\
6to y $7 \mathrm{mo}$ & 4 & Transportación Turística \\
$8 \mathrm{vo}$ & 5 & Catering Turístico \\
$9 \mathrm{no}$ & 6 & Promoclón y Eventos Turisticos \\
$10 \mathrm{mo}$ & 7 & Patrimonio Turistlco Ambiental \\
$13 \mathrm{ero}$ & 8 & Facilitación Turística Local \\
$17 \mathrm{mo}$ & 9 & Recreaclón Local \\
$18 \mathrm{vo}$ & 10 & Ilativo con la Legislaclón Turística \\
\hline
\end{tabular}

En concordanciaa loantesexpresado, yen estricto acatamientoal ordenamiento jurídico, la recién sancionada Ley de Turismo trata el asunto de las competencias municipales en el artículo $18^{\circ}$, mediante el cual, el Poder Central delega en los municipios las funciones que se citan textualmente (Congreso..., 1992: 12)

1. La clasificación de proyectos turisticos.

2. La clasificación de establecimientos de alojamiento y la autorización para su funcionamiento.

3. La inspección y fiscalización de los senvicios turisticos que presten las personas naturales y juridicas integrantes del Sistema Turistico.

4. Los que deleguen en cada caso por la vía de convenio la Corporación de Turismo de Venezuela.
- Parte organizativa

Las estructuras organizativas, cuyo objetoserá el de ejecutar las competencias que por mandato de las Leyes, le son atribuidas, se encuentran amparada en el t VI de la Organización del Poder Municipal, Capítulo I, Sección Primera, artículo $49^{\circ}$ al $75^{\circ}$ (Congreso..., 1989). Tendrá una Dirección del Turismo con rango de unidad de línea adscrita a la alcaldía; además, previa decisión del Consejo Municipal, tiene la alternativa de poder funcionar como un ente descentralizado del tipo del Instituto Autónomo Municipal, Empresa o Fundación Municipal, tal como lo prevé el título $\mathrm{V}$ de los Entes Descentralizados del municipio en sus artículos $42^{\circ}$ al $48^{\circ}$ respectivamente (Congreso..., 1989).

\section{La Superestructura Turistica}

Delimitadas las competencias, el paso seguiente, consiste en determinar el orden, tipo, jerarquía y escala administrativa de las Instituciones Públicas y Organizaciones Privadas que conforman el espectro macrosectorial del Turismo, a las que competen acciones de coordinación y dirección superior.

Una definición oficialmente publicada de superestructura turistica es inexistente, algunos autores han presentado acepciones a partir de las variables que la caractcrizan por convención o por extensión; dando como resultado que, de la revisión bibliográfica de este aspecto una evidencia de la superficialidad y escasez con lo cual ha sido trabajado el tema.

Boullon(1985:31) incorpora a la superestructura turistica a la ecuación del sistema turistico a la vez que le imprime la facultad de controlar la funcionalidad e interrelación de los otros subsistemas componentes de este todo.

Como tal, se le puede entonces definir, como:

El conjunto de Instituciones Públicas (pertenecientes a la Administración PúblicaIntergubernamental e Interministerial), y Organizaciones Privadas (Cámaras, Federaciones, Asociaciones y Colegios Profesionalismo) encargadas de regular, controlar, optimizar, centralizar ias funciones de coordinación y dirección al más alto niveí, asi como arbitrar los intereses heterogéneos de los entes oficiales y privados a los fines de velar por la calidad del producto global que se ofrece en los mercados nacionales internacionales (Rodriguez Acevedo, 1996).

La superestructura turistica es entonces, la parte del gran sistema que planifica, ejecuta y evalúa; es también responsable de totalizar y conjugar a los demás componentes del sistema constituido en su fondo y forma por un proceso fundamentalmente de mercado, donde se conectan las magnitudes de la oferta con la demanda mediante la venta del producto turistico y en la que participa así mismo a estructura productiva de la actividad (Rodríguez Acevedo, 1996: 15). 
Como ya se ha estipulado, desde el punto de vista del tipo y carácter de las instituciones u organizaciones, la superestructura turistica armoniza una variada gama de competencias y funciones que pueden ser visualizadas en el Cuadro 3, curyo diseño ha sido adaptado al caso de estudio para Venezuela, en la que se destaca la dimensión de las funciones que en los actuales momentos realiza el Municipio como ente asociado al macro-sector público.

CUADRO 3 - DISIRIBUCIÓN FUNCIONAL POR TPO DE INSTIUCIÓN PÚBLICA INTERGUBERNAMENTAL E INTERMINISTERIAL

\begin{tabular}{|c|c|c|}
\hline Funckst & incloubenamental & f. Intorninktortal \\
\hline $\begin{array}{l}\text { 1. Leglslación } \\
\text { aplicada, normativa } \\
\text { de la actlvidad }\end{array}$ & $\begin{array}{l}\text { - Congreso de la } \\
\text { República } \\
\text { - Ministerlos } \\
\text { - Gobernaciones } \\
\text { - Munlclpios }\end{array}$ & - Minsterio de Adscripclón \\
\hline $\begin{array}{l}\text { 2. Planlficaclón } \\
\text { aplicada, } \\
\text { Investigaclón y } \\
\text { ordenamlento } \\
\text { territorial }\end{array}$ & $\begin{array}{l}\text { - Oficinas Centrales } \\
\text { - Ministerios } \\
\text { - Gobernaclones } \\
\text { - Municlplos }\end{array}$ & $\begin{array}{l}\text { - Cordllplan/OCEl } \\
\text { - Corporaclones Reglonaies y } \\
\text { Fundaclones de Desarrolio } \\
\text { Regionai } \\
\text { - Ministerio del Ambiente } \\
\text { - Ministerio Desarrollo Urbano }\end{array}$ \\
\hline $\begin{array}{l}\text { 3. Asignación de } \\
\text { presupuestos para } \\
\text { el funcionamiento de } \\
\text { los organismos } \\
\text { públicos }\end{array}$ & $\begin{array}{l}\text { - Congreso de la } \\
\text { República } \\
\text { - Oficina Central } \\
\text { - Gobernaciones } \\
\text { - Municipios }\end{array}$ & $\begin{array}{l}\text { - Ocepre } \\
\text { - Fondo de Inverslones } \\
\text { - Ministerlo de Haclenda }\end{array}$ \\
\hline 4. Facilltación turística & $\begin{array}{l}\text { - Ministerios } \\
\text { - Gobemaciones } \\
\text { - Municiplos }\end{array}$ & $\begin{array}{l}\text { - Ministerios de Relaciones Exteriores } \\
\text { - Ministerio de Relaciones Interiores } \\
\text { - Dir. de Identlficación \& Extranjería } \\
\text { - Ministerio de Haclenda } \\
\text { - Ministerio de Agrlcultura y Cría } \\
\text { - Ministeric de Transporte y } \\
\text { - Comunicaclones } \\
\text { - Ministerio del Ambiente } \\
\text { - Instituto Nacional de Parques } \\
\text { - Policias y Cuerpos de Seguridad } \\
\text { del Estado/Gobernaclones/ } \\
\text { Munlclplo } \\
\text { - Oficina Regional de Asuntos } \\
\text { Indigenas }\end{array}$ \\
\hline
\end{tabular}

continuación Cuadro 3

\begin{tabular}{|c|c|c|}
\hline 25 & 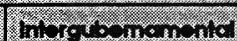 & 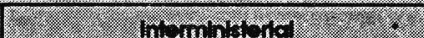 \\
\hline $\begin{array}{l}\text { 5. Desarrollo de } \\
\text { Infraestructuras } \\
\text { Bósicas y de } \\
\text { Equlpamiento } \\
\text { Tuństico }\end{array}$ & $\begin{array}{l}\text { - Ministerlos } \\
\text { - Gobernociones } \\
\text { - Municipios }\end{array}$ & $\begin{array}{l}\text { - Ministerio de Transporte y } \\
\text { Comunicaciones } \\
\text { - DGS. Vlalidad } \\
\text { - Ministerlo de Desarrollo Urbano } \\
\text { - DGS. Desarrollo Urbanistico } \\
\text { - Instituto Nacional de Parques } \\
\text { - CANTV/CADAFE/INOS }\end{array}$ \\
\hline $\begin{array}{l}\text { 6. Control de los } \\
\text { Transportes y } \\
\text { operaciones de las } \\
\text { Comunlcaciones }\end{array}$ & $\begin{array}{l}\text { - Ministerios } \\
\text { - Gobernaciones }\end{array}$ & $\begin{array}{l}\text { - Ministerio de Transporte y } \\
\text { Comunicaciones } \\
\text { - DGS de Tránsito Terrestre } \\
\text { - DGS de Tránsito Aéreo } \\
\text { - DGS de Tránsito Acuático } \\
\text { - Capitanía de Puerto } \\
\text { - I.a. Aeropuerto Internacional } \\
\text {-Simón Bolnar" } \\
\text { - I.a. Administración de Ferrocarriles } \\
\text { dei Estado/FERROCAR } \\
\text { - Instituto Nacional de Puertos } \\
\text { - CANTV } \\
\text { - IPOSTEL }\end{array}$ \\
\hline $\begin{array}{l}\text { 7. Educación Formal. } \\
\text { Formación } \\
\text { Profesional. } \\
\text { Capacltación y } \\
\text { Adiestramiento } \\
\text { Aspectos Laborales y } \\
\text { Sindlcales }\end{array}$ & - Ministerios & $\begin{array}{l}\text { - Ministerio de Educación } \\
\text { - Dirección de Educación Media y } \\
\text { Diversificada } \\
\text { - Dirección de Educación Superior } \\
\text { - División de Institutos Privados } \\
\text { - Consejo Nacional de Universidades } \\
\text { - Ministerio del Trabajo } \\
\text { - DGS de Economía y Empleo } \\
\text { - Ince-Turismo }\end{array}$ \\
\hline $\begin{array}{l}\text { 8. Prestación de } \\
\text { servlcios Directos a la } \\
\text { Demanda Turistica } \\
\text { Nacional e } \\
\text { Intemocional }\end{array}$ & $\begin{array}{l}\text { - Institutos Autóno- } \\
\text { mos, Empresas, } \\
\text { Comparios y } \\
\text { Fundaciones dei } \\
\text { Estado } \\
\text { - Gobernociones } \\
\text { - Municlpios }\end{array}$ & $\begin{array}{l}\text { - Instituto Nacional de Capacitación } \\
\text { y Recreación de los Trabajadores } \\
\text {-INCRET } \\
\text { - I.A. Administración Ferrocarriles del } \\
\text { Estado/FERROCAR } \\
\text { - Instituto Nacional de Parques } \\
\text { - Fundación dei Niño } \\
\text { - Corporación de Turismo } \\
\text { - Sistemas Teleféricos } \\
\text { - Centro Simón Bolinar } \\
\text { - Hoteles }\end{array}$ \\
\hline
\end{tabular}

Fuente: Fundamentación Teórica del Turismo USB/NUL ACTUALIZADO - 1993 


\section{Conclusiones}

La concepción evolutiva del Turismo Venezolano desde la perspectiva de la Organización Pública ha coincidido en cierta manera con las etapas cumplidas en otros países de reconocida trayectoria, dado el siguiente orden:

a) fase de incorporación

Comienzaa título muy primarioa considerárselecomounaspecto económico que debía ser dotado de una legislación aplicada y de una estructura organizativa cónsona, incorporándose dentro del rango burocrático con la figura de Oficina de Turismo en año 1938

b) fase de fomento estatal

Ubicada específicamente durante el Gobierno Dictatorial de Marcos Pérez Jiménez (1949-1958), caracterizada desde el punto de vista organizacional por elevarse la jerarquía de Oficina a Dirección de Turismo a la que se le dotó de funciones más definidas y controles administrativos orientados a facilitar la gestión de las empresas prestadoras de servicios; a ello, se le suma una política de acrecentamiento y modernización del parque de habitaciones hoteleras promovidas desde el sector público además de la creación de un Instituto y una Ciudad Vacacional para adelantar los programas de Turismo Social y los Sistemas Teleféricos (Cerro El Avila y Mérida) como parte de la diversificación de la oferta de servicios turísticos y recreativos;

c) fase de expansión

Transcurrido unos años (década de los sesenta y setenta), el devenir democrático abre paso a la expansión del sector oficialista a través de una política de crecimiento burocrático y centralización concentrado casi exclusivamente en el poder nacional, medidas que descansan en el establecimiento de varios Ministerios, Instituciones Autónomos, Fundaciones y Compañias Anónimas que apoyan la afinidad y complementariedad con el turismo; le sigue la promulgación de la Segunda Ley de Turismo a la cual se adosa la figura de la Corporación de Turismo de Venezuela y la Incorporación de la actividad en los planes nacionales de desarrollo;

d) fase de ajuste del mercado y de la descentralización administrativa

Inmediatamente después de las medidas cambiarias del año 1983, se han venido vislumbrando ciertos comportamientosen laestructura del mercado turístico, los cuales se manifiestan de manera objetiva en el crecimiento interanual de la demanda internacional receptiva; en el mejoramiento de los ingresos por concepto de balanza de pagos turística y en los niveles de inversión nacional e internacional; así como también, en el dimensionamiento del rol y de las funciones que se atribuyen para sí la Administración Central, cuest

ley de Turismo. No obstante, ambos aspectos continuan inexorablemente atados a ley de Turismo. petrolera; es por ello que, en aras de conseguir un equilibrio natural de las fuerzas tanto a nivel de mercado como del tamaño del aparato burocrático, el Estado ha decidido emplear las siguientes políticas:

i) LIBERACIÓN TARIFARÍA de los servicios hoteleros y del transporte aéreo, sincerándola con la estructura de costos y con la dinámica del sector.

ii) PRIVATIZACIÓN de la red hotelera y de las Líneas Aérea Internacional y doméstica de la nación.

iii) CIELOS ABIERTOS para la aviación internacional.

iv) CONVERSIÓN de deuda externa en inversión interna.

v) PROMOCIÓN INTERNACIONAL conjunta con la empresa privada en los principales eventos y bolsas de turismo a nivel mundial.

vi) EJECUCIONDELAS TRANSFERENCIASDE COMPETENCIAS en materia turística, en concordancia conla Ley Orgánica dedelimitación, descentralización y transferencia de competencias del poder público.

Sobreéste último punto, referidoal delas "Transferenciasde Competencias" se debeacotarque, a pesarde su indispensable necesidad, el nivel de Administración Central no le ha prestado hasta los momentos la debida atención; la promulgación de esta Ley consigue a una actividad que persiste en desarrollarse en un ambiente organizacional, desactualizado si se considera relativamentela dinámica y pujanza del Turismo.

El excesivo centralismo imperante en los últimos treinta años ha institucionalizado una acentuada rigidez e inoperancia en la superestructura turística tanto a nivel nacional como regional y municipal que la mantiene injustamente reprimida, negándole la versatilidad y capacidad de eficiencia esperada por el conjunto de actores sociales, institucionales e individuales representados tanto por la comunidad receptora, los organismos oficiales, los prestadores de servicios así como por los mismo turistas.

Esta línea u orientación conduce de un modo directo a abogar por una disposición concertada entre los sectores públicos y privado que satisfagan las necesidades e intereses de la comunidad en su más amplia concepción; ahora bien, partiendo del valor sine qua non del basamento organizacional, se considerará el caracter fundamental del Municipio comoámbito geográfico-administrativo donde se debería de promover y regular a la actividad, ya que en la práctica se presenta como:

- el marco de encuentro turista-comunidad receptora; 
- sitio donde se genera la atención y seguridad primaria hacia la demanda;

- punto donde se localizan los usos y vocaciones del espacio físico adscrito territorialmente;

- es el nivel admitido a escala de mercado turístico con múltiples inferencias en cuanto a lo socioeconómico, político, cultural y ambiental de la localidad 0 jurisdicción municipal;

- es el lugar de advenimiento empresarial en el cual se desarrollan y cumplen las funciones de Catastro, Ingeniería Municipal, Tributación Local, Promoción Institucional, Explotación de Áreas o Servicios bajo el régimen de concesiones, arrendamientos o por contratos de operación; aspectos importantes que influyen en la consecución o deserción de los proyectos de inversión y sociedades de comercio prestadoras de servicios turísticos.

Lo expresado hasta este momento, en un orden estrictamente cronológico, sirve para justificar una problentática que no ha sido lo suficientemente apreciada a pesar de su imponderabletrascendencia, si seconsidera a la superestructura como el marco general y dentro de sí a el municipio en particular, debido a que se muestran como hechos complementarios e individuales que no pueden ser separados en su origen, caracterización así como en la forma en que ambos afectan el campo de acción de las Empresas Turísticas.

\section{Referencias Bibliogrăficas}

ALESSI, R. 1990. Derecho administrativo.

BOULLON, Roberto C. 1985. Planificación del espacio turístico. $]^{\text {era }}$, México: Serie Turismo, Editorial Trillas. COMISIÓN PARA LA REFORMA DEL ESTADO/COPRE. 1995. Cuadernos para la reforma administrativa. SP. 1989. Dinámica organizacional de las gobernaciones y bases de un nuevo sistema de gestión. Caracas.

CONGRESO DE LA REPÚBLICA. 1989. Ley orgánica de régimen municipal. Gaceta Oficial, Caracas, 14/6/89. 1992. Ley de Turismo. Caracas, 21/12/92.

JACOME, J.M. 1975. La planificación administrativa para el desarrollo económico y social en Latinøamérica. Caracas: Edic. de la Biblioteca/Colección de ciencias económicas.

KRAPF, Kurt. 1963. Le role et l'importance du turisme internacional. Berne: Verbanosdruckerei ag.

RODRÍGUEZ ACE VEDO, Rafael. 1987. Fundamentación teórica del turismo. Venezuela: Universidad Simón Bolívar. NUL. Unidad Curricular.

1996. Indicadores para historiografiar el turismo-sintesis cronológica comparada. Estudios y Perspectivas del

Turismo, Buenos Aires: v. 6, n. 2, abr. 97. 